\title{
A INTERAÇÃO DO CICLO DA EXPERIÊNCIA DE KELLY COM O CÍRCULO HERMENÊUTICO-DIALÉTICO PARA A CONSTRUÇÃO DE CONCEITOS DE BIOLOGIA
}

\section{The interaction of Kelly's experience circle with the hermeneutic-dialectic circle for the construction of concepts in Biology}

\begin{abstract}
Ricardo Ferreira das Neves ${ }^{1}$ • Ana Maria dos Anjos Carneiro-Leão ${ }^{2}$. Helaine Sivini Ferreira ${ }^{3}$
\end{abstract}

\begin{abstract}
Resumo: A pesquisa investigou o uso da temática contemporânea bioplásticos, para a construção dos conceitos: degradação, biodegradação e decomposição. Os alunos apresentaram dificuldades em sua construção, possivelmente porque envolviam fenômenos em nível molecular, que exigem grande capacidade de abstração, e, também, porque os aspectos que diferenciam esses processos entre si são bastante sutis. Os bioplásticos são bastante adequados nesse tipo de intervenção, visto que podem ser facilmente confeccionados nos laboratórios da escola e possibilitariam a observação in loco dos processos biológicos. Os pressupostos teóricos deste trabalho foram a Teoria dos Construtos Pessoais (Ciclo da Experiência) e a metodologia hermenêutica-dialética. Os resultados indicam que, inicialmente, os alunos tiveram dificuldades com questões relacionadas à terminologia e à percepção dos fenômenos em escala micro. Contudo, as concepções finais dos mesmos (individuais e coletivas) foram significativamente alteradas, pois os conceitos trabalhados se encontram muito próximos das definições científicas formais encontradas na literatura da área.
\end{abstract}

Palavras-chave: Bioplásticos. Processos biológicos. Ciclo da Experiência de Kelly. Círculo Hermenêutico-Dialético.

\begin{abstract}
The research investigated the use of bioplastics as a contemporary theme for the construction of the concepts of degradation, biodegradation and decomposition. The students had difficulties in their construction, possibly because they involved phenomena at the molecular level, which require a large capacity of abstraction and also because the aspects that differentiate between these processes themselves are fairly subtle. Bioplastics are quite appropriate to this kind of intervention, because they can be manufactured in laboratories in the school and would allow on-site observation of biological processes. The theoretical presuppositions of this work were the Theory of Personal Constructs (Cycle Experiment) and hermeneutic-dialectic methodology. The results indicate that initially the students had difficulties with the terminology and issues related to the perception of the phenomena on a micro scale. However, their final designs (individually and collectively) were significantly altered, because concepts were very close to the formal scientific definitions found in the literature of the area
\end{abstract}

Keywords: Bioplastics. Biological processes. Kelly’s Experience Cycle. Hermeneutic-Dialectic Circle.

\footnotetext{
${ }^{1}$ Centro Acadêmico de Vitória, Universidade Federal de Pernambuco. Rua Alto do Reservatório, s/n ${ }^{\circ}$, Bela Vista. Vitória de Santo Antão, PE, Brasil. 55.608-680.rico.neves@bol.com.br

${ }^{2}$ Departamento de Morfologia e Fisiologia Animal, Universidade Federal Rural de Pernambuco. Recife, PE, Brasil.

${ }^{3}$ Departamento de Educação, Universidade Federal Rural de Pernambuco. Recife, PE, Brasil.
} 
Neves, R. F.; Carneiro-Leão, A. M. A.; Ferreira, H. S.

\section{Introdução}

Os Parâmetros Curriculares Nacionais (PCN) da área de Ciências da Natureza, Matemática e suas Tecnologias (BRASIL, 2000) para a disciplina de Biologia ressaltam a importância das discussões sobre os conceitos de biodegradação, degradação e decomposição como essenciais para a compreensão dos ciclos da natureza, da reciclagem, do lixo e de outros temas relacionados ao meio ambiente. Contudo, o que se tem observado é que a abordagem destes conceitos implica uma grande capacidade de abstração por parte dos alunos, uma vez que se tratam de processos que são invisíveis à vista desarmada (a olho nu). Para Zuanon e Diniz (2003), esta é uma dificuldade percebida, também, por parte dos professores, que têm dificuldade em ensinar conceitos, teorias e princípios que ocorrem a partir de processos que não são concretamente observáveis, o que frequentemente resulta numa abordagem inadequada de muitos fenômenos celulares e moleculares. Outro aspecto que dificulta a construção desses conceitos é o fato de ocorrerem de modo sequenciado e, eventualmente, concomitante na natureza, e se distinguirem entre si por aspectos bastante sutis.

Tendo em vista estas questões, esta pesquisa utilizou a temática contemporânea, os bioplásticos ou plásticos verdes para contextualizar, em sala de aula, a construção dos conceitos de degradação, biodegradação e decomposição. Esses materiais são plásticos biodegradáveis, derivados inteiramente, ou quase, de matérias-primas renováveis. Vêm sendo produzidos a partir de tecnologias limpas, e, por serem biodegradáveis, têm menor impacto sobre o meio ambiente (STEVENS, 2002). Nesta perspectiva, os bioplásticos parecem ser bastante adequados, visto que podem ser facilmente confeccionados nos laboratórios da escola. E, por apresentarem tempo de vida útil relativamente curto, podem ser utilizados em intervenções nas quais os alunos efetivamente observariam in loco os processos de degradação, biodegradação e decomposição.

Para tanto, essa pesquisa está fundamentada na Teoria dos Construtos Pessoais de George Kelly (1963), mais especificamente no Corolário da Experiência, e na metodologia hermenêutica-dialética; e espera-se que a utilização conjunta desses aportes teóricos possa vir a trazer contribuições relevantes na construção dos conceitos de degradação, biodegradação e decomposição, bem como para as pesquisas no ensino de ciências.

Assim, temos como objetivo investigar o processo de construção dos conceitos de degradação, biodegradação e decomposição a partir do estudo de bioplásticos, utilizando, conjuntamente, o Ciclo da Experiência de Kelly e o Círculo Hermenêutico-Dialético (CHD).

\section{A teoria dos construtos pessoais de George Kelly}

George Kelly nasceu em 28 de abril de 1905, em uma fazenda nas proximidades de Perth, no Kansas, EUA. Filho de pai educador, sua escolarização foi irregular, mas seus pais educadores supriram sua educação, ao lado do filho. Kelly cursou o Ensino Médio em Wichita e passou três anos na "Friends University"; formou-se em física e matemática no "Park College", e estudou sociologia educacional na Universidade de Kansas.

A Teoria dos Construtos Pessoais de Kelly (1963) foi utilizada nesta pesquisa, como embasamento teórico, estruturando condições de se descreverem as interpretações e as estratégias para a aprendizagem dos alunos, na qual representa um conjunto de teorias psicológi- 
A interação do ciclo da experiência de Kelly ...

cas, associadas às teorias ativas do conhecimento, considerando que as pessoas aprendem, ou constroem conhecimentos, a partir de interações com representações da realidade (HALL; LINDZEY; CAMPBELL, 2000).

Esse conjunto de teorias psicológicas pertence à linha cognitivista, partindo do princípio de que uma pessoa, ao nascer, traz consigo algumas estruturas cognitivas, e essas são responsáveis por suas coordenações, organizações e direcionamentos nos processos psicológicos, sendo, então, condição básica para iniciar o processo de construção do conhecimento (COLL et al., 2000). Para tanto, Kelly (1963) desenvolveu trabalhos com relação à aprendizagem, adotando uma postura construtivista, vendo o homem como um cientista, sempre prevendo e antecipando eventos. Para Kelly (1963, p. 47, tradução nossa), "os processos de uma pessoa são psicologicamente canalizados pelas maneiras por meio das quais ela antecipa eventos".

Segundo Kelly (1963), os seres humanos constroem sua realidade na qual respondem, e sua resposta está direcionada pelas suas experiências, utilizando conceitos prévios similares para antecipar as consequências do comportamento (HALL; LINDZEY; CAMPBELL, 2000). Desta forma, a teoria proposta por Kelly (1963, p. 47, tradução nossa) é fundamentada em um postulado "Os processos de uma pessoa são psicologicamente canalizados pelas formas com que ela antecipa eventos" e 11 corolários, sendo estes: Corolário da Construção, Experiência, Organização, Individualidade, Dicotomia, Faixa, Escolha, Modulação, Comunalidade, Fragmentação e Sociabilidade. Entretanto, nesta pesquisa, buscou-se enfocar apenas o Corolário da Experiência.

\section{O Corolário da Experiência}

No Corolário da Experiência, é possível compreender que o sistema de construção de uma pessoa varia conforme a réplica do evento. Kelly (1963) considera que os seres humanos, ao se depararem com diversas situações ou eventos, tendem a selecionar certas características, o que ele chama de construto. Assim, cada pessoa constrói sua situação de uma maneira própria, alternativa. O Corolário da Experiência é apresentado nos seguintes termos: "O sistema de construção de uma pessoa varia à medida que ela sucessivamente constrói réplica dos eventos” (KELLY, 1963, p. 72, tradução nossa). Dessa forma, pode-se dizer que uma pessoa experimenta algo quando consegue construir uma réplica desse evento e que se pode alcançar uma mudança conceitual, ou seja, mudanças de construtos ou mudança nos sistemas de construção.

Segundo Bastos (1992), a maneira pela qual a pessoa muda seus sistemas de construtos, é, então, relatada pelo Corolário da Experiência, no qual as construções pessoais são hipóteses de trabalho, que se confrontam com as experiências, estando sujeitas à revisão e recolocação. O sistema de elaboração cognitiva de uma pessoa varia conforme a interpretação de eventos reprodutíveis (HALL; LINDZEY; CAMPBELL, 2000). É importante mencionar que essa experiência, para Kelly, não representa apenas um simples encontro com um evento, mas um ciclo contendo cinco fases: antecipação, investigação, encontro, confirmação ou desconfirmação, e revisão construtiva (KELLY, 1963).

A Figura 1 ilustra sucintamente cada uma das etapas que compõem o Ciclo da Experiência de Kelly. 
Neves, R. F.; Carneiro-Leão, A. M. A.; Ferreira, H. S.

- Antecipação: essa etapa inicia-se quando a pessoa tenta antecipar o evento, utilizando os construtos que possui no seu sistema de construção;

- Investimento: quando a pessoa realiza a fase anterior, dependendo de sua capacidade de construir a réplica do evento, ela acaba por se engajar na fase de investimento, quando se prepara para encontrar-se com o evento;

- Encontro: nesse encontro, a pessoa checa suas teorias pessoais;

- Confirmação ou desconfirmação (validação): a checagem dessas teorias conduz à confirmação ou desconfirmação das mesmas;

- Revisão construtiva: após a confirmação ou desconfirmação da teoria, surge uma revisão dos pontos que geraram problemas. Essa revisão poderá levar à formação de novas construções dessa relação.

Figura 1. Representação do Ciclo da Experiência de Kelly

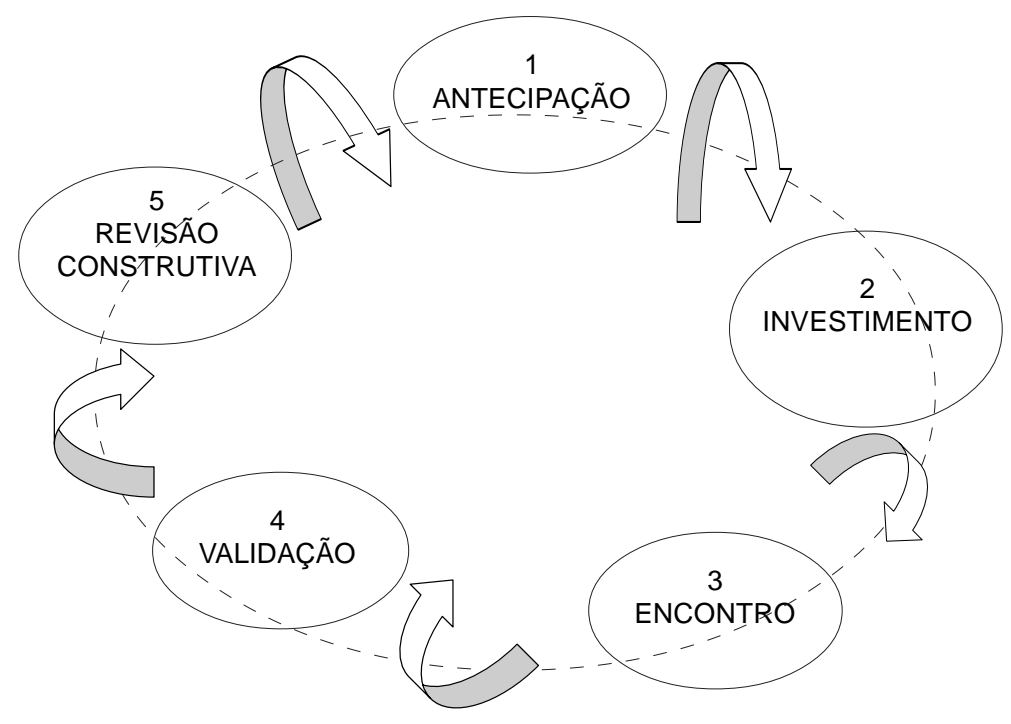

Fonte: Neves (2006).

\section{O Círculo Hermenêutico-Dialético (CHD)}

A hermenêutica representa a busca da compreensão de sentido que se dá na comunicação entre os seres humanos, destacando-se a mediação, o acordo e a unidade de sentido; enquanto a dialética consiste em um processo em que existem diálogos, críticas, análises, construções e reconstruções coletivas, chegando a um consenso mais próximo da realidade (MINAYO, 2000). Desta forma, a hermenêutica-dialética leva à compreensão do texto, da fala, 
do depoimento como resultantes de um processo social e de um processo de conhecimento, cada qual com significado específico, porém, articulados entre si (BARBOSA, 2001).

Nessa perspectiva, tem-se a metodologia que foi descrita por Guba e Lincoln (1989), baseando-se em um referencial pluralista-construtivista ou descrito como Avaliação de Quarta Geração, o qual menciona a técnica do Círculo Hermenêutico-Dialético (CHD), como uma ferramenta para coleta de dados, pois estabelece diálogos e discussões grupais, em que os envolvidos podem analisar e refletir sobre diferentes aspectos (OLIVEIRA, 2005). A Figura 2 ilustra uma representação esquemática do modelo do CHD.

Figura 2. Hermeneutic Dialectic Circle

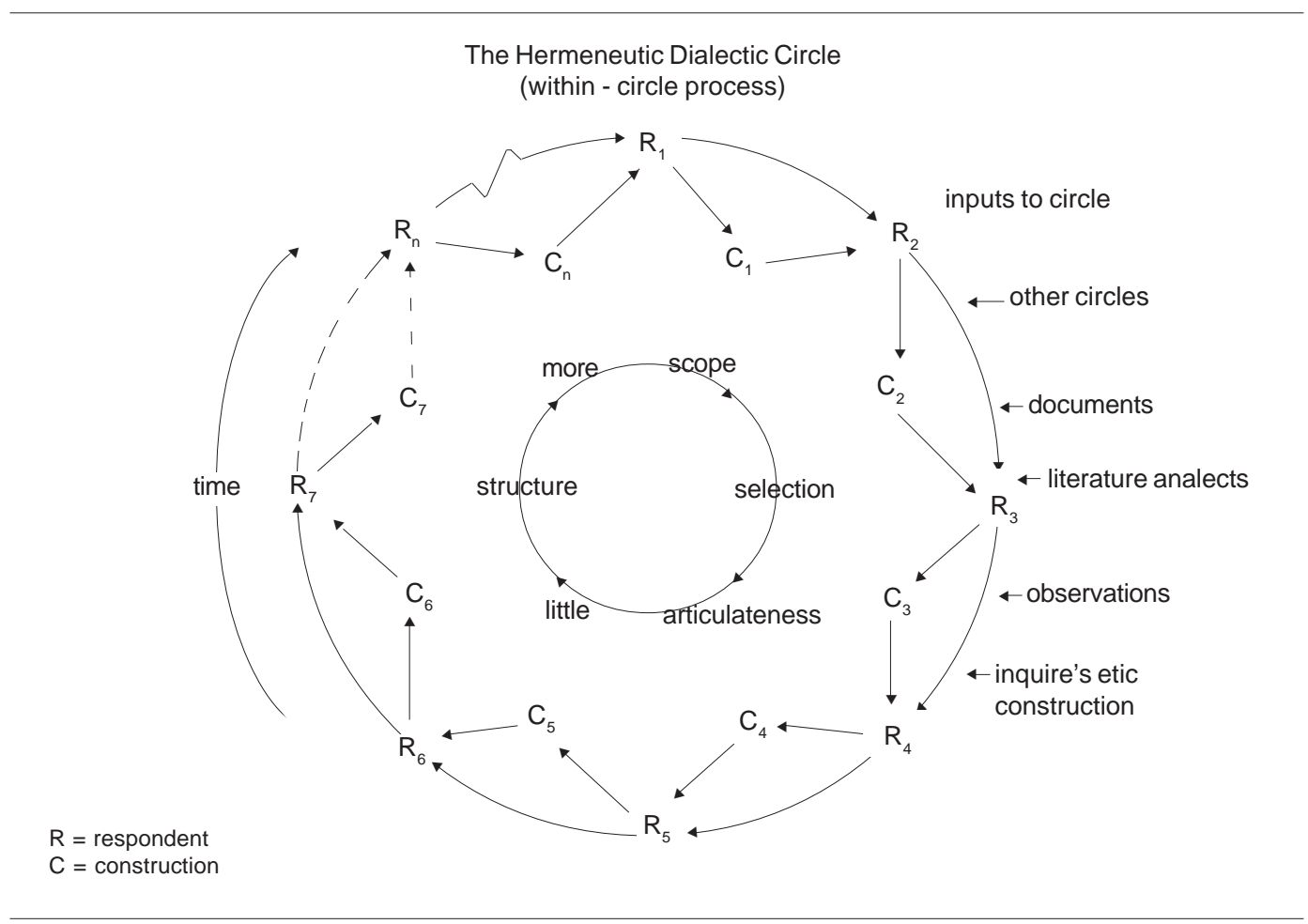

Fonte: Guba e Lincoln (1989, p. 152).

Com relação à Figura 2, R1 representa o entrevistado, que, a partir de seus relatos, iniciará as primeiras construções, caracterizadas como C1, servindo como subsídios para o segundo entrevistado, e, assim, sucessivamente (FURTADO, 2001). No CHD, inicialmente, é feita uma entrevista e, logo a seguir, uma síntese dos dados coletados, para ser apresentada a uma segunda pessoa, à qual deve ser solicitado um comentário e o acréscimo de novos dados e sugestões (OLIVEIRA, 1999). Então, mediante a técnica do CHD é possível verificar com 
Neves, R. F.; Carneiro-Leão, A. M. A.; Ferreira, H. S.

profundidade as reflexões iniciais, finais e grupais, das reflexões apresentadas (OLIVEIRA, 2005).

\section{Bioplásticos ou plásticos verdes}

Estes plásticos "amigos da natureza” foram definidos por Stevens (2002) como plásticos que são biodegradáveis, ou seja, cujos componentes são derivados, inteiramente ou quase inteiramente, de fonte renovável, e que podem ser produzidos a partir de misturas entre polímeros naturais ou biossintéticos, desde que haja a incorporação de um agente plastificante e, eventualmente, outros aditivos, que são utilizados de acordo com as características do material a ser produzido.

Este material, além de ter forte afinidade por água (hidrofilico), ainda não é tóxico e, se incinerado ou submetido a processo de compostagem, pode retornar ao ecossistema na forma de $\mathrm{CO}_{2}$ (ROSA et al., 2002). Isto é possível pelo fato de sua cadeia principal possuir átomos de oxigênio ou nitrogênio intercalados com átomos de carbono. Desta forma, os bioplásticos têm um futuro extremamente promissor, por causa das suas características especiais (biodegradabilidade, compostabilidade, biocompatibilidade, hidrofilia, entre outras) e de suas amplas aplicações, que são, em muitos casos, superiores a muitos polímeros sintéticos.

\section{Os processos de degradação, biodegradação e decomposição}

\section{A degradação}

Segundo Souza e Lopes (1993) e Santos et al. (1999), está relacionada com a perda de propriedades ou a perda de características que o material apresentará ao longo do tempo, ou seja, este sofre uma modificação em sua aparência, ocasionada por alteração em suas propriedades físicas ou em sua estrutura química. Assim, um produto, seja natural ou sintético, ao ficar exposto ao intemperismo, perderá certas características e propriedades, o que pode ser verificado através de uma modificação na estrutura desse material, implicando uma diminuição de sua qualidade e de seu desempenho. Vale ressaltar que a degradação pode se caracterizar em: fotodegradação (os raios ultravioletas); quimiodegradação (despolimerização do material ou reações de catálise) e biodegradação (LIMA, 2004).

\section{A biodegradação}

A biodegradação consiste na degradação de materiais, através da ação de organismos vivos (ROSA et al., 2002). Nesse processo é possível que determinadas substâncias possam ser descompostas em constituintes básicos, por ação microbiológica; sendo, então, um processo indispensável para a reciclagem dos elementos na biosfera, o que garante a restituição desses, na formação e crescimento dos organismos. Vale ressaltar que, embora existam vários seres envolvidos no processo de biodegradação, (bactéria, fungos), alguns fatores - como: temperatura, umidade do solo, acidez, disponibilidade de oxigênio e quantidade de lixo também podem interferir, e se verifica que todos esses fatores abióticos modificam ou agem sobre as vias metabólicas dos organismos citados.

Assim, sem as bactérias e outros microrganismos em cooperação, a Terra sofreria destruição pelo seu próprio processo natural, por meio de galhos, folhas de árvores e animais 
mortos, que se acumulariam no ambiente (PELCZAR JR. et al., 1996). Diante do exposto, pode-se resumir que a biodegradação parte do princípio de que todo composto sintetizado biologicamente pode ser decomposto biologicamente, sendo um resultado do processo de digestão, assimilação e metabolização, do composto orgânico, por ação de bactérias, fungos, protozoários e outros microrganismos (PELCZAR JR. et al., 1996).

\section{A decomposição}

A decomposição pode ser descrita como um processo natural, em que ocorre transformação de moléculas orgânicas complexas, em componentes inorgânicos mais simples, tornando-os disponíveis no ambiente para serem utilizados pelos seres vivos (CHANDRA; RUSTGI, 1998). Nessa perspectiva, entende-se que os microrganismos decompositores, ao liberarem suas enzimas, permitem que haja quebra da cadeia molecular, dissociando as moléculas, liberando os átomos, e estes poderão ser reintroduzidos no meio ambiente e/ou utilizados como fonte de alimento para si ou para outros seres (ROSA et al., 2002). Vale ressaltar que não só esses seres participam do processo, mas, também, verifica-se a presença de macro-organismos, como minhocas, cupins, larvas, insetos e nematóides, que cooperam mutuamente para a decomposição da matéria (CAMPBELL, 1995).

Desta forma, a manutenção da produtividade do ecossistema depende da transformação da matéria orgânica e, consequentemente, da biomassa microbiana no solo, pois estes realizam a ciclagem de nutrientes (PELCZAR; ROGER; CHAN, 1981; VALPASSOS et al., 2001; BRAGA et al., 2002). Então, é imprescindível que a matéria seja biodegradável, para que ocorra a sua decomposição e sua assimilação, permitindo a utilização e reutilização dos elementos constituintes, o que possibilita uma série de atividades metabólicas realizadas por inúmeros seres vivos. Desta forma, toda a matéria orgânica sintetizada na Terra, quando decomposta, pode restituir, ao meio, os elementos que a integram, mantendo o equilíbrio biológico e ecológico.

\section{Metodologia}

Esta pesquisa foi desenvolvida com vinte alunos do $3^{\circ}$ ano do Ensino Médio. Estes participaram dos sete encontros baseados no Ciclo da Experiência de Kelly. Contudo, para a coleta dos dados, apenas cinco alunos foram escolhidos aleatoriamente para participar do Círculo Hermenêutico-Dialético (CHD), o qual foi realizado com este grupo menor nas etapas de antecipação e revisão construtiva. A intervenção ocorreu em nove encontros, que foram estruturados de acordo com o Ciclo da Experiência de Kelly (1963), que descreve a experiência como um ciclo de cinco etapas: antecipação, investimento, encontro, confirmação/desconfirmação (validação) e revisão construtiva. Os dois encontros sobressalentes correspondem à aplicação do CHD com o grupo de cinco alunos nas etapas de antecipação e revisão construtiva. Então, o CHD foi aplicado no questionamento: Você poderia explicar o que entende por degradação, biodegradação e decomposição?

A coleta dos dados foi através da metodologia interativa, o Círculo Hermenêutico Dialético (CHD) (OLIVEIRA, 1999). A partir dessa ferramenta, foi possível coletar as concepções dos alunos sobre os conceitos de degradação, biodegradação e decomposição. É im- 
Neves, R. F.; Carneiro-Leão, A. M. A.; Ferreira, H. S.

portante mencionar que a opção por este instrumento de coleta de dados foi feita tendo em vista o seu caráter interativo e dinâmico, que possibilita uma maior aproximação entre o pesquisador e os alunos, permitindo, ainda, uma multiplicidade de interpretações. Vale ressaltar que, devido à complexidade envolvida na aplicação desse instrumento de coleta de dados e, também, pela dificuldade para reunir todos os alunos em horário extraclasse, apenas os cinco alunos escolhidos aleatoriamente participaram, efetivamente, da aplicação do CHD, conforme a Figura 3.

Figura 3. CHD (A - aluno entrevistado, $\mathbf{C}$ - construção teórica e $\mathbf{P}$ - pesquisador)

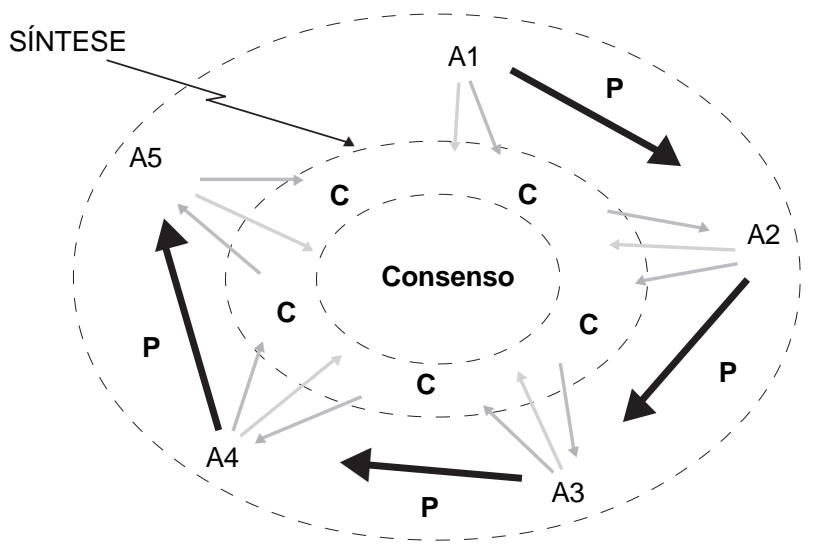

Fonte: Neves (2006).

Assim, temos: o primeiro círculo pontilhado representa o grupo de alunos entrevistados, enquanto o segundo círculo simboliza a dinâmica do "vaivém" das construções e reconstruções teóricas. O terceiro círculo representa o ponto de culminância da metodologia, visto que é, nesta etapa, que os alunos têm oportunidade para colocar seus comentários conjuntamente e construir a concepção que representa o consenso do grupo sobre o assunto em questão. No centro do círculo, a palavra "consenso" representa o resultado do encontro final com todos os entrevistados, para colocarem seus comentários e críticas, concluindo a pré e pós-análise dos dados.

Desta forma, inicialmente, coletaram-se as construções teóricas individuais do primeiro aluno. Estas serão apresentadas ao segundo aluno após a coleta de suas construções teóricas individuais. Desta forma, o segundo aluno tem a oportunidade de alterar ou não suas construções em função das colocações do entrevistado anterior. Então, para permitir que, na análise dos resultados, haja uma diferenciação entre as construções individuais e as construções individuais modificadas, adotou-se a seguinte terminologia: C, para construção individual e C' caso haja modificações na colocação inicial do indivíduo. E, assim, a dinâmica se repete até que o último aluno seja entrevistado. O CHD é finalizado quando ocorre um encontro 
final com a presença de todos os entrevistados, para discussão coletiva e registro de novas informações, fase esta denominada de consenso.

\section{A integração do CHD no Ciclo da Experiência}

Como comentado anteriormente, a coleta dos dados foi feita mediante o CHD (OLIVEIRA, 1999), sendo esta ferramenta inserida nas etapas de antecipação e revisão construtiva do Ciclo da Experiência. A inserção do CHD nessas duas etapas se deve ao fato de que a primeira etapa (antecipação) é considerada, por Kelly, como o momento em que deve expor, ao indivíduo, informações que o permitam refletir e começar a utilizar seus construtos para checar as teorias. Já a última etapa, considerada como revisão construtiva, é o momento final do ciclo, em que se verificou se ocorreu à mudança conceitual, sobre o tema tratado, conforme a Figura 4.

Figura 4. A inserção do CHD no Ciclo da Experiência.

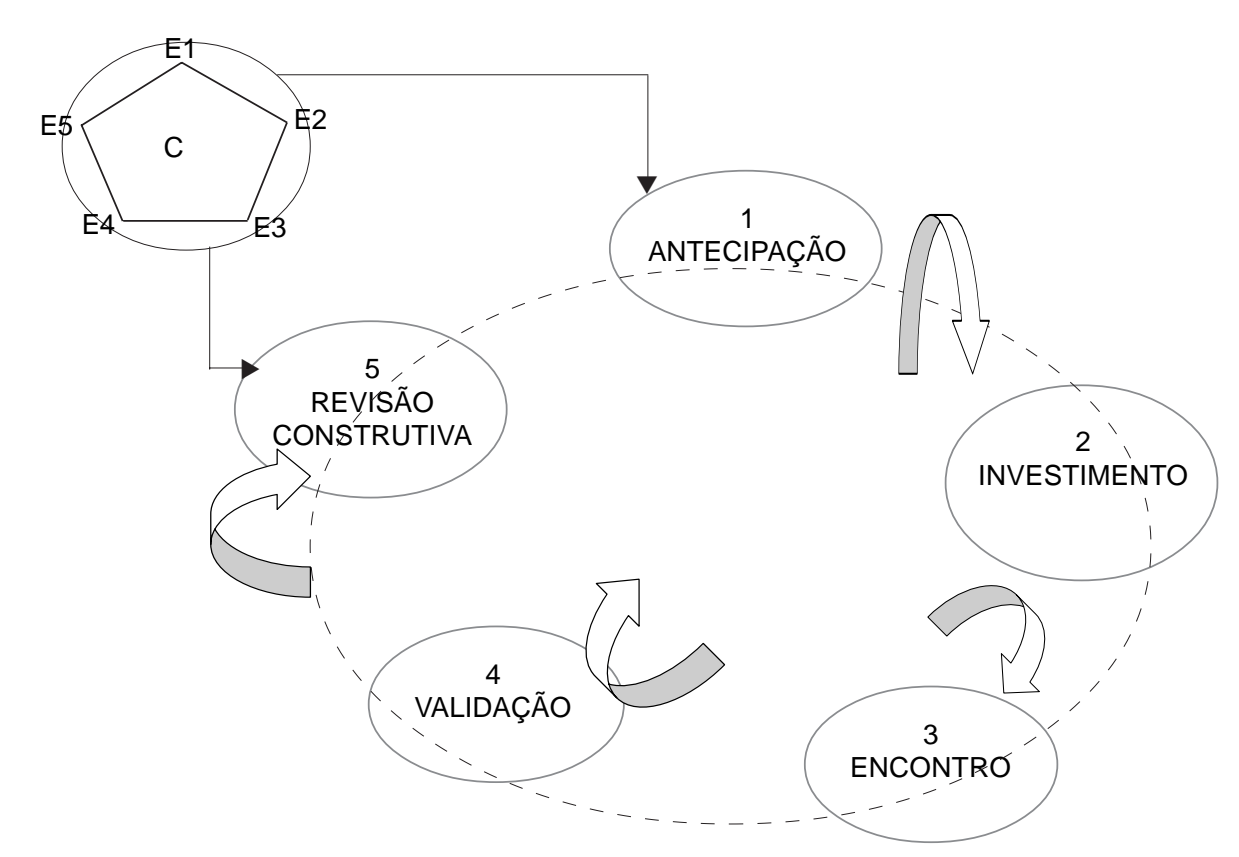

Fonte: Neves (2006).

\section{Os encontros fundamentados no Ciclo da Experiência}

A primeira etapa do Ciclo da Experiência, a antecipação, ocorreu em dois encontros: o primeiro foi com todo o grupo, e teve como objetivo apresentar o tema da pesquisa e a 
Neves, R. F.; Carneiro-Leão, A. M. A.; Ferreira, H. S.

relevância de se estudar tal conteúdo, bem como seria a estruturação dos encontros e a sua duração; o segundo foi realizado apenas com os cinco alunos, e teve como objetivo coletar as concepções prévias dos mesmos sobre os conceitos de degradação, biodegradação e decomposição através do CHD.

A segunda etapa do Ciclo da Experiência, o investimento, ocorreu em apenas um encontro, do qual participaram todos os alunos. Esse encontro teve como objetivo construir conceitos relacionados aos polímeros, estabelecendo as diferenças entre esses materiais, tanto do ponto de vista estrutural como do ponto de vista de propriedades.

A terceira etapa do Ciclo da Experiência, o encontro, ocorreu apenas em um momento, e que teve como objetivo confeccionar um bioplástico. A confecção do bioplástico utilizado neste trabalho foi realizada de forma artesanal, baseando-se em uma receita disponível no livro de Stevens (2002, p. 168).

A quarta etapa do Ciclo da Experiência, etapa de Confirmação ou Desconfirmação (validação), foi realizada em três encontros, e teve como objetivos iniciais: analisar as diferenças entre os polímeros e expor as amostras à ação de intempéries. Assim, no primeiro momento, o material confeccionado na etapa anterior foi analisado juntamente com produtos sintéticos e naturais, e foram expostos ao intemperismo, para serem novamente analisados em período de oito dias.

A última etapa, a revisão construtiva, ocorreu em dois encontros, e teve como objetivo verificar a compreensão final sobre os conceitos de degradação, biodegradação e decomposição, e quanto ela havia sido alterada em função da intervenção vivenciada. No primeiro momento, os alunos foram convidados a uma pequena reflexão acerca da ligação íntima entre seres humanos e o meio ambiente. E, em seguida, analisar, em conjunto, os pontos positivos e negativos do trabalho. No segundo momento, foi aplicado o CHD (pós-teste), com o objetivo de verificar as concepções finais dos cinco alunos sobre os conceitos de degradação, biodegradação e decomposição, o que finalizou a intervenção.

\section{Resultados e discussão}

Nos quadros 1, 2 e 3 temos algumas considerações feitas pelos alunos antes e após a intervenção, de forma individual e coletiva (consenso), quando arguidos sobre os conceitos de degradação, biodegradação e decomposição.

\section{Considerações sobre as respostas apresentadas no Quadro 1}

Ao se analisarem as concepções iniciais dos alunos sobre o conceito de degradação, observa-se que foram muito vagas. Foi comum o uso de terminologias como "destruição" e "desaparecimento", o que remete a construções puramente intuitivas. Com exceção do aluno A5, que referiu-se a um processo de modificação do material, e, neste caso, utilizou uma terminologia muito próxima da definição científica. De acordo com Souza e Lopes (1993) e Santos et al. (1999), a degradação consiste num processo no qual se tem a perda de propriedades ou características de um determinado material, o que implica uma modificação de sua aparência, ocasionada por alteração em suas propriedades físicas ou em sua estrutura química. 
A interação do ciclo da experiência de Kelly ...

Quadro 1. Construções teóricas iniciais dos alunos (etapa anterior à intervenção), ao serem questionados sobre os processos de degradação, biodegradação e decomposição.

\begin{tabular}{|c|c|c|}
\hline Degradação & Biodegradação & Decomposição \\
\hline $\begin{array}{l}\text { CA1: A destruição ou } \\
\text { desaparecimento dos materiais } \\
\text { por algum motivo. }\end{array}$ & $\begin{array}{l}\text { CA1: Ocorre da mesma forma da } \\
\text { degradação, mas há intervenção de } \\
\text { alguma coisa biológica, destruição } \\
\text { ou desaparecimento com a } \\
\text { intervenção de um meio biológico. }\end{array}$ & $\begin{array}{l}\text { CA1: Não seria destruir, mas } \\
\text { retirar, diminuir alguma coisa da } \\
\text { composição do material. }\end{array}$ \\
\hline $\begin{array}{l}\text { CA2: Desaparecimento de um } \\
\text { material. }\end{array}$ & $\begin{array}{l}\text { CA2: Não ocorre da mesma forma } \\
\text { que a degradação, mas tem alguma } \\
\text { coisa biológica. }\end{array}$ & $\begin{array}{l}\text { CA2: Desaparecimento de um } \\
\text { material, por alguns meses, anos, } \\
\text { ou algum meio biológico vai } \\
\text { decompondo. }\end{array}$ \\
\hline $\begin{array}{l}\text { CA3: Degradação é a ação do } \\
\text { homem. }\end{array}$ & CA3: É ação do ambiente. & CA3: Acabar o material. \\
\hline $\begin{array}{l}\text { CA4: Desaparecimento natural } \\
\text { de algum material. } \\
\text { CA5: Quando um material sofre } \\
\text { algum tipo de modificação. As } \\
\text { substâncias vão sofrendo } \\
\text { alguma modificação, reagem e } \\
\text { vão se dissolvendo formando } \\
\text { uma modificação no meio. }\end{array}$ & $\begin{array}{l}\text { CA4: Ocorre praticamente igual à } \\
\text { degradação, só em matérias } \\
\text { diferentes. } \\
\text { CA5: Mais ou menos parecida com } \\
\text { a degradação, quase a mesma } \\
\text { coisa que degradação, sendo que, } \\
\text { pode ser que se modifique mais } \\
\text { rápido, que se degrade mais rápido, } \\
\text { que desapareça mais rápido por ser } \\
\text { uma bio. }\end{array}$ & $\begin{array}{l}\text { CA4: A diluição de um material } \\
\text { com o passar dos anos. } \\
\text { CA5: Quando eles estão } \\
\text { desaparecendo, quando os } \\
\text { materiais de uma forma diferente, } \\
\text { já não ter mais a mesma forma, o } \\
\text { mesmo sentido, eles são } \\
\text { modificados, se modificando e } \\
\text { desaparecimento. É uma } \\
\text { modificação e um } \\
\text { desaparecimento do material. } \\
\text { Primeiro sofre modificação para } \\
\text { depois desaparecer, e desaparece } \\
\text { gradativamente. }\end{array}$ \\
\hline
\end{tabular}

C: construção teórica inicial

Fonte: Neves (2006).

Com relação à concepção de biodegradação, os alunos A1, A2 e A5, inicialmente, perceberam que existe alguma relação entre esta concepção e a de degradação. Também perceberam que há um processo biológico envolvido, contudo, não foram capazes de ir além e explicitar, por exemplo, o papel dos micro-organismos. Para Rosa et al. (2002) e Braga et al. (2002), a biodegradação consiste na degradação de materiais, por meio da ação de organismos vivos, em um processo que permite que determinadas substâncias possam ser descompostas em constituintes básicos, por ação microbiológica.

Ao se analisarem as concepções dos alunos quanto ao conceito de decomposição, percebeu-se, novamente, a presença de terminologias tais como: desaparecimento, destruição e diluição, utilizadas pelos alunos. De acordo com Chandra e Rustgi (1998), a decomposição é um processo natural muito complexo, visto que envolve transformações de moléculas orgânicas, em componentes inorgânicos mais simples, de modo a torná-los disponíveis no ambiente para serem utilizados pelos seres vivos. 
Neves, R. F.; Carneiro-Leão, A. M. A.; Ferreira, H. S.

Quadro 2. Construções teóricas iniciais e modificadas dos alunos (etapa posterior à intervenção), ao serem questionados sobre os conceitos de degradação, biodegradação e decomposição.

\begin{tabular}{|c|c|c|}
\hline Degradação & Biodegradação & Decomposição \\
\hline CA1: É a destruição de um material. & $\begin{array}{l}\text { CA1: É a destruição de um } \\
\text { material, com a ação de alguns } \\
\text { seres da natureza, por exemplo, } \\
\text { bactérias e fungos. }\end{array}$ & $\begin{array}{l}\text { CA1: É a transformação de } \\
\text { material desgastado em um } \\
\text { outro tipo de material, não o } \\
\text { mesmo. }\end{array}$ \\
\hline $\begin{array}{l}\text { CA2: Perda de características, } \\
\text { propriedades do material, perda da } \\
\text { aparência. No começo o material era } \\
\text { constituído de uma coisa, mas depois } \\
\text { passou a perder essa constituição, } \\
\text { essas propriedades, que tinha no } \\
\text { começo, e que depois de algum tempo } \\
\text { não tem mais. A degradação é } \\
\text { subdivida em fotodegradação pela luz } \\
\text { solar, a quimiodegradação pelas } \\
\text { enzimas e biodegradação pelos } \\
\text { microrganismos. }\end{array}$ & $\begin{array}{l}\text { CA2: Se relaciona com a } \\
\text { degradação. Os } \\
\text { microorganismos vivos, que } \\
\text { existem no ambiente e ao redor } \\
\text { da gente, agem sobre o } \\
\text { material. e relaciona com a } \\
\text { degradação" ambiente ao redor } \\
\text { da gente, , fazendo com ele } \\
\text { penetrem nas estruturas, e vai } \\
\text { decompondo. A biodegradação } \\
\text { pode ocorrer na forma aeróbica } \\
\text { e anaeróbica. Na biodegradação } \\
\text { fungos e bactérias e outros } \\
\text { microorganismos que existem } \\
\text { na natureza, atuam no material, } \\
\text { também os fatores naturais } \\
\text { água, solo, umidade. }\end{array}$ & $\begin{array}{l}\text { CA2: Ter um material bem } \\
\text { complexo e ir se decompondo } \\
\text { aos poucos, se formando num } \\
\text { material mais simples, e daí } \\
\text { servi de alguma utilidade para } \\
\text { o ser vivo. }\end{array}$ \\
\hline $\begin{array}{l}\text { CA3: É quando o produto está } \\
\text { perdendo características. Existem três } \\
\text { tipos de degradação; a fotodegradação } \\
\text { pela luz, a quimiodegradação pelas } \\
\text { enzimas, que cada uma tem sua função } \\
\text { e a biodegradação pelas bactérias e } \\
\text { fungos. } \\
\text { *Crítica para A1 - "É a destruição de } \\
\text { um material": deu a entender que é } \\
\text { instantaneamente, e não é assim } \\
\text { instantaneamente, existem certos } \\
\text { processos; certas fases. }\end{array}$ & $\begin{array}{l}\text { CA3: É a atuação dos } \\
\text { microrganismos no material. }\end{array}$ & $\begin{array}{l}\text { CA3: É um produto complexo } \\
\text { que é transformado numa } \\
\text { substância mais simples para } \\
\text { favorecer o meio. }\end{array}$ \\
\hline $\begin{array}{l}\text { CA4: Modificação na estrutura na } \\
\text { estrutura física e química do material, } \\
\text { na aparência. }\end{array}$ & $\begin{array}{l}\text { CA4: É a decomposição do } \\
\text { material sobre a ação de } \\
\text { microrganismos. }\end{array}$ & $\begin{array}{l}\text { CA4: É a quebra da reação } \\
\text { de um material orgânico } \\
\text { composto, para um simples } \\
\text { inorgânico.C'A4: Um produto } \\
\text { complexo é transformado } \\
\text { numa substância mais } \\
\text { simples para favorecero } \\
\text { meio. }\end{array}$ \\
\hline $\begin{array}{l}\text { CA5: É a perda de características e de } \\
\text { propriedades, de um determinado } \\
\text { material. Esse material pode sofrer } \\
\text { alteração tanto química quanto física. A } \\
\text { degradação pode ocorrer pela } \\
\text { quimiodegradação (pelas enzimas), } \\
\text { fotodegradação quando o material sofre } \\
\text { alteração pela os raios ultravioleta do sol, } \\
\text { e biodegradação (pelos microrganismos, } \\
\text { como fungos e bactérias). }\end{array}$ & $\begin{array}{l}\text { CA5: É a ação dos } \\
\text { microrganismos como bactérias } \\
\text { e fungos, que tem em seus } \\
\text { componentes as enzimas para } \\
\text { quebrar um determinado } \\
\text { material, a sua estrutura para } \\
\text { que possa ser assimilado ao } \\
\text { meio. Pode ser aeróbica e } \\
\text { anaeróbica. }\end{array}$ & $\begin{array}{l}\text { CA5: É quando um material } \\
\text { passar de um estágio macro } \\
\text { para micro e ocorre perda de } \\
\text { característica na sua } \\
\text { composição e a sua estrutura } \\
\text { passa para um estagio mais } \\
\text { simples, e esse estágio mais } \\
\text { simples, ele beneficia a sua } \\
\text { assimilação ao meio. }\end{array}$ \\
\hline
\end{tabular}

C (construção teórica inicial) e C' (construção teórica modificada)

Fonte: Neves (2006). 
Quanto às concepções modificadas, não se observou o processo de reconstrução por parte dos alunos, um indício claro de que os processos dialéticos presentes no CHD, que auxiliam os processos cognitivos e que podem levar à reconstrução, podem ocorrer apenas em um determinado ponto, pois além dessa etapa é necessário que os próprios alunos tenham um maior embasamento conceitual para evoluir.

\section{Considerações sobre as respostas apresentadas no Quadro 2}

Em linhas gerais pode-se dizer que, após a nova aplicação do CHD ao término da intervenção didática, as maiores modificações observadas nas construções dos alunos foram sobre o conceito de degradação. O grupo explicitou concepções associadas ao conceito principal, como quimiodegradação, fotodegradação e biodegradação. Também se destaca o surgimento de alguns aspectos, tais como: a transformação de materiais ou objetos de dimensões macroscópicas em moléculas e compostos de dimensões microscópicas, e sua posterior quebra em elementos mais simples (átomos). Ainda que estes aspectos não estejam claros nas construções dos alunos, merecem ser mencionados como indicativo de vislumbrar elementos de um universo molecular e atômico, como componentes da matéria.

No que concerne, especificamente, ao conceito de biodegradação, vale apenas destacar algumas construções elaboradas pelos alunos, através das quais pode-se observar seu grau de evolução em relação ao conceito trabalhado. $\mathrm{O}$ aluno A2, por exemplo, explicou que, para se realizar esse processo, há necessidade de os microrganismos atuarem em conjunto com fatores abióticos. Novamente, o aluno A2, juntamente com o aluno A5, explicitaram que a biodegradação poderia ocorrer sob duas formas, aeróbica e anaeróbica, conforme Braga et al. (2002), mas não fizeram menção aos produtos finais desses processos com relação à ausência ou presença de oxigênio.

Esses alunos também tentaram descrever como o processo de biodegradação poderia ocorrer: o aluno A2 elaborou a seguinte sequência, microrganismos - materiais (estrutura) - decomposição; enquanto a sequência do aluno A5 foi: microrganismos - enzimas - materiais (estrutura) assimilação. Desse modo, percebeu-se que os alunos começaram a considerar e a utilizar elementos fora da escala visual, para poderem descrever o processo. Por fim, no que concerne ao processo de decomposição, o grande diferencial observado foi a percepção de que há transformação de um material mais complexo em um mais simples, e que isso traz benefícios ao meio ambiente.

Quanto às considerações modificadas, observaram-se, apenas, para o conceito de decomposição, sendo importante mencionar que, ao longo de todo o processo, seja antes ou depois da intervenção, o aluno A5 foi o que apresentou maior número de re-construções, e acreditamos que essas re-construções se devam ao fato de esse aluno ser o último no círculo de entrevistas, tendo acesso a todas as construções dos outros alunos. Desta forma, este pôde utilizá-las para re-estruturar suas construções teóricas iniciais, incorporando novas informações e terminologias. Também é importante considerar a disposição do aluno em analisar a opinião dos outros e rever a sua própria, o que nos remete a aspectos da personalidade do indivíduo, como o seu grau de comunicação, de compromisso e de extroversão.

No que concerne aos aspectos da personalidade de um indivíduo, Hall, Lindzey e Campbell (2000) mencionam que a construção da realidade ou de sua interpretação está rela- 
Neves, R. F.; Carneiro-Leão, A. M. A.; Ferreira, H. S.

cionada com o sistema de construtos pessoais desenvolvidos pelo ser humano, e o que se verificou é que, quando o indivíduo revisa as suas colocações, este tende a re-construir suas opiniões de maneira mais bem explanada. O aluno A5, por meio de suas colocações, remete ao Corolário da Escolha. Bastos (1992) explicita que, a partir de seu envolvimento no ciclo, o indivíduo pode modificar suas concepções sobre os conceitos observados mediante a experiência vivenciada. Assim, esse aluno foi o que mais apresentou tal perspectiva, uma vez que reviu suas colocações, analisou suas hipóteses, explicitou suas ideias, realizou suas interpretações individuais da realidade presente, e isso o fez se engajar no processo e participar deste.

Um ponto relevante a ser destacado nessa seção, diz respeito à consideração feita pelo aluno A3 para o aluno A1, na qual o primeiro aluno criticou a ideia do segundo, quanto a sua colocação sobre o processo de degradação, salientando que, para ocorrer tal processo, são necessárias certas fases. Esse fato é importante, visto que, em outro momento, até então, não havia sido verificada tal postura por parte de nenhum dos alunos, embora, para cada pergunta, tenha sido solicitado que eles poderiam fazer algum comentário ou crítica sobre as colocações dos outros. Isso pode ter acontecido porque este aluno compreendeu que fazendo algum comentário ou crítica sobre as respostas do outro, em nenhum momento, desconsiderava sua colocação, nem tampouco menosprezava o seu colega quanto ao seu conhecimento do processo em discussão.

Quadro 3. Construções teóricas iniciais e modificadas dos alunos (consensos), coletadas em etapa anterior (inicial) e posterior (final) à intervenção pedagógica.

\begin{tabular}{|c|l|l|}
\hline \multicolumn{1}{|c|}{ Conceitos } & \multicolumn{1}{|c|}{ Inicial } & \multicolumn{1}{c|}{ Final } \\
\hline Degradação & $\begin{array}{l}\text { É a destruição, } \\
\text { desaparecimento ou } \\
\text { modificação dos } \\
\text { materiais. }\end{array}$ & $\begin{array}{l}\text { Perda das características e propriedades de um } \\
\text { determinado material, podendo sofrer alteração tanto } \\
\text { química, quanto física. A degradação é subdividida em } \\
\text { quimiodegradação (ação de enzimas através de } \\
\text { microrganismos); fotodegradação (pela luz solar) e } \\
\text { biodegradação (pelos microrganismos fungos e bactérias). }\end{array}$ \\
\hline Biodegradação & $\begin{array}{l}\text { Tem algo ligação com a } \\
\text { degradação, só que } \\
\text { agora por um processo } \\
\text { biológico. }\end{array}$ & $\begin{array}{l}\text { Tem ligação com a degradação. É a decomposição da } \\
\text { matéria sobre a ação de microrganismos, e outros fatores } \\
\text { que existem na natureza: água, solo e umidade. Pode } \\
\text { ocorrer de duas formas: aeróbica ou anaeróbica, através } \\
\text { dos fungos e bactérias }\end{array}$ \\
\hline Decomposição & $\begin{array}{l}\text { É o desaparecimento } \\
\text { gradativamente de um } \\
\text { material. }\end{array}$ & $\begin{array}{l}\text { É quando o material para de um estado macro para micro e } \\
\text { ocorrendo a perda de características na sua composição, e } \\
\text { a sua estrutura passa de um estágio mais simples, } \\
\text { facilitando a sua assimilação ao meio. Existem outros seres } \\
\text { que participam do processo da decomposição como } \\
\text { minhocas e insetos. }\end{array}$ \\
\hline
\end{tabular}

Fonte: Neves (2006).

\section{Considerações sobre as respostas apresentadas no Quadro 3}

Observa-se que a concepção inicial do grupo sobre o conceito de degradação se apresentou muito vaga, visto que envolve processos de "destruição", de "desaparecimento" e 
de modificação dos materiais. A "destruição" e o "desaparecimento" mencionados pelos alunos consistem numa terminologia do senso comum, estando intimamente relacionada a conclusões meramente intuitivas. Assim, não há qualquer base científica dando sustentação a esses processos tal como colocados pelos alunos. Já quando mencionou o processo de modificação do material, o grupo usou uma terminologia mais próxima da definição científica, uma vez que, de acordo com Souza e Lopes (1993) e Santos et al. (1999), a degradação consiste num processo no qual se tem a perda de propriedades ou características de um determinado material, implicando uma modificação de sua aparência, o que seria ocasionado por alteração em suas propriedades físicas ou em sua estrutura química.

É possível perceber que, na concepção do grupo sobre degradação, já existiam alguns elementos, como a modificação de materiais, que estão na definição científica do conceito, mas estes não foram adequadamente explorados. Após a intervenção e nova aplicação do CHD, observou-se que a concepção do grupo sobre a degradação foi significativamente modificada, de forma a quase coincidir com as definições de Souza e Lopes (1993) e Santos et al. (1999). Além disso, o grupo ainda explicitou as subdivisões do processo em quimiodegradação, fotodegradação e biodegradação.

Quanto à biodegradação, os alunos, inicialmente, perceberam existir relações entre esta concepção e a de degradação e que havia um processo biológico envolvido, sem serem capazes, contudo, de ir além e explicitar, por exemplo, o papel dos micro-organismos. Já no consenso final, observou-se, mais uma vez, que o grupo construiu uma concepção muito próxima da concepção científica, visto que mencionou a ação dos micro-organismos, o papel dos fatores abióticos e, ainda, os tipos de biodegradação (aeróbica ou anaeróbica). Para Rosa et al. (2002) e Braga et al. (2002), a biodegradação consiste na degradação de materiais, através da ação de organismos vivos, em um processo que permite que determinadas substâncias possam ser descompostas em constituintes básicos, por ação microbiológica. O processo de biodegradação pode ocorrer em solo ou na água, e, dependendo do tipo de micro-organismo envolvido, pode acontecer em fase aeróbica ou anaeróbica. Ainda de acordo com estes autores, a biodegradação é indispensável para a reciclagem dos elementos na biosfera, garantindo a restituição desses, na formação e crescimento dos organismos.

Assim, ao se comparar à concepção final construída pelo grupo com as definições científicas de Rosa et al. (2002) e Braga et al. (2002), mencionadas acima, observou-se que os alunos só não mencionaram a questão da biodegradação enquanto um processo de reciclagem da natureza. Por fim, ao se observar a concepção de decomposição construída pelo grupo, percebe-se a recorrência da terminologia "desaparecimento" num indício claro da predominância do senso comum e falta de conhecimento sobre o processo. A decomposição pode ser descrita como um processo natural, em que ocorre uma transformação das moléculas orgânicas complexas, em componentes inorgânicos mais simples, tornando-os disponíveis no ambiente, para serem (re) utilizados pelos seres vivos (CHANDRA; RUSTGI, 1998).

Apesar de o consenso inicial do grupo ter sido muito aquém do esperado, pode-se observar que, após a intervenção, houve uma melhoria significativa na concepção final. Desta forma, verificou-se que o grupo pontuou aspectos tais como: a transformação de materiais ou objetos de dimensões macroscópicas em moléculas e compostos de dimensões microscópicas, e sua posterior quebra em elementos mais simples (átomos). É importante mencionar que essas ideias ainda não estão explicitadas claramente pelos alunos, contudo, acredita-se que a 
Neves, R. F.; Carneiro-Leão, A. M. A.; Ferreira, H. S.

sua presença no discurso deles já seja bastante significativa. Também é importante destacar que não apenas a decomposição parece ter sido compreendida, pois os resultados indicam que a questão da assimilação também foi nitidamente percebida, em substituição à ideia de desaparecimento dos materiais.

\section{Considerações finais}

No que concerne à utilização do tema contemporâneo bioplásticos como elemento de contextualização para a construção dos conceitos de degradação, biodegradação e decomposição, requer-se uma abordagem multidisciplinar, pois, em alguns casos, é necessário pontuar aspectos de outras áreas (biologia, ecologia, química e materiais) para se obter melhor compreensão desses conceitos biológicos. Como já comentado anteriormente, abordagens contextualizadas e multidisciplinares trazem inúmeros benefícios para os processos de ensinoaprendizagem, visto que tornam os processos mais significativos e menos fragmentados, ao vincularem conteúdos da base nacional comum com temas contemporâneos da atualidade.

Com a utilização do círculo hermenêutico-dialético (CHD) como ferramenta para a coleta de dados, por meio de seu caráter dinâmico e interativo, foi possível identificar os obstáculos epistemológicos que podem comprometer a aprendizagem dos alunos. Essas dificuldades envolviam questões relacionadas, sobretudo, à terminologia e conceituação de processos e percepção de fenômenos na escala micro. A aplicação do CHD também se mostrou muito válida, visto que possibilitou não apenas a coleta das concepções dos alunos, mas sua eventual reconstrução individual e na coletividade.

Ao se estruturar a intervenção didática nas cinco etapas que compõem o Ciclo da Experiência de Kelly, tanto o professor como os alunos são beneficiados. O primeiro porque adequa o seu conjunto de atividades didáticas a uma sequência preestabelecida, com base em uma teoria cognitiva, enquanto o aluno usufrui de uma sequência que visa estimular, ao máximo, os seus processos cognitivos, propiciando maior aprendizagem.

\section{Referências}

BARBOSA, R. H. S. Mulheres, reprodução e AIDS: as tramas da ideologia na assistência à saúde de gestantes HIV+. 2001. 310f. Tese (Doutorado em Saúde Pública) - Escola Nacional de Saúde Pública, São Paulo, 2001.

BASTOS, H. F. B. N. Changing teachers' practice: towards a constructivist methodology of physics teaching. 1992. 438 p. Thesis (Doctoral - Philosophy) - Department of Educational Studies, University of Surrey, Guildford, 1992.

BRAGA, B. et. al. Introdução a engenharia ambiental. São Paulo: Prentice Hall, 2002.

BRASIL. Secretaria de Educação Fundamental. Parâmetros curriculares nacionais: ciências da natureza, matemática e sua tecnologias. Brasília: MEC; SEF, 2000. 
A interação do ciclo da experiência de Kelly ...

CAMPBELL, S. Manual de compostagem para hortas e jardins: como aproveitar bem o lixo orgânico doméstico. São Paulo: Nobel, 1995.

CHANDRA, R.; RUSTGI, R. Biodegradable polymers. Progress in Polymer Science, Elmsford, v. 23, n. 7, p. 1273-1335, 1998.

COLL, C. et al. Os conteúdos na reforma: ensino e aprendizagem de conceitos, procedimentos e atitudes. Porto Alegre: Artes Médicas, 2000.

FURTADO, J. P. Um método construtivista para a avaliação em saúde. Ciência \& Saúde Coletiva, Rio de Janeiro, v. 6, n. 1, p. 165-181, 2001.

GUBA, E.; LINCOLN, Y. S. Fourth generation evaluation. Newbury Park: Sage, 1989.

HALL. C. S.; LINDZEY, G.; CAMPBELL, J. B. Teorias da personalidade. 4. ed. Porto Alegre: Artmed, 2000.

KELLY, G. A. A theory of personality: the psychology of personal constructs. New York: Norton, 1963.

LIMA, S. L. T. Reciclagem e biodegradação de plásticos. Revista Científica do IMAPES, Sorocada, v. 2, n. 2, p. 28-34, abr. 2004.

LOPES, A. C. Os parâmetros curriculares nacionais para o ensino médio e a submissão ao mundo produtivo: o caso do conceito de contextualização. Educação \& Sociedade, Campinas, v. 23, n. 80, p. 386-400, set. 2002.

MINAYO, M. C. S. O desafio do conhecimento: pesquisa qualitativa em saúde. 7. ed. São Paulo: Hucitec; Abrasco, 2000.

NEVES, R. F. A interação do ciclo da experiência de Kelly com o círculo hermenêutico-dialético, para a construção de conceitos de biologia. 2006. $108 f$. Dissertação (Mestrado em Ensino das Ciências) - Universidade Federal Rural de Pernambuco, Recife, 2006.

OLIVEIRA, M. M. Formation en associativisme et développement local dans le Nord-Est du Brésil: l'experience de Camaragibe. 1999. 320f. Thèse (Ph. D.) - Université de Sherbrooke, Sherbrooke, 1999.

Como fazer pesquisa qualitativa. Recife: Bagaço, 2005.

PELCZAR, M. J.; ROGER, R.; CHAN, E. C. S. Microbiologia. São Paulo: McGraw-Hill do Brasil, 1981. v. 2.

PELCZAR JR., M. J. et al. Microbiologia. São Paulo: Makron Books, 1996.

ROSA, D. S. et al. Avaliação da biodegradação de poli- $\beta$-(hidroxibutirato), poli- $\beta$ (hidroxibutirato-covalerato) e poli-1-1-(caprolactona) em solo compostado. Polímeros, São Carlos, v. 12, n. 4, p. 311-317, oct./dez. 2002.

SANTOS, A. S. F. et al. Estudo da influência de resíduos catalíticos na degradação de plásticos reciclados (Blenda HDPE/PP e PET) provenientes de lixo urbano. Polímeros, São Carlos, v. 9, n. 4, p. 189-194, out./dez. 1999. 
Neves, R. F.; Carneiro-Leão, A. M. A.; Ferreira, H. S.

SOUZA, J. P.; LOPES, J. C. Cresce interesse por degradáveis. Plástico Moderno, São Paulo, n. 230, p. 15-17, mar. 1993.

STEVENS, E. S. Green plastics: an introduction to the new science of biodegradable plastics. Woodstock: Princeton University Press, 2002.

VALPASSOS, M. A. R. et al. Effects of soil management systems on soil microbial activity, bulk density and chemical properties. Pesquisa Agropecuária Brasileira, Brasília, v. 36, n. 12, p. 1539-1545, dez. 2001.

ZUANON, A, C, A.; DINIZ, R. E. S. Aulas de biologia e a participação dos alunos: conhecendo como um grupo de estudantes do ensino médio avalia uma experiência. In: ENCONTRO NACIONAL DE PESQUISA EM EDUCAÇÃO EM CIÊNCIAS, 4., 2003, Bauru. Atas... Bauru: ENPEC, 2003.

Artigo recebido em 21/11/2011. Aceito em 06/03/2012. 